\title{
A three-dimensional finite element
} analysis of the relationship between masticatory performance and skeletal malocclusion

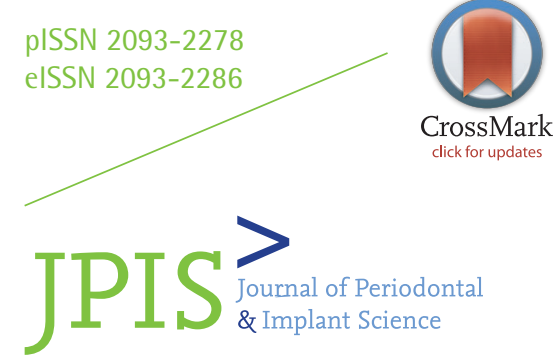

\author{
Jung-Chul Park' ${ }^{1}$ Hyun-Seung Shin ${ }^{1}$, Jung-Yul Cha ${ }^{2}$, Jong-Tae Park ${ }^{3, *}$ \\ 'Department of Periodontology, Dankook University College of Dentistry, Cheonan, Korea \\ ${ }^{2}$ Department of Orthodontics, Yonsei University College of Dentistry, Seoul, Korea \\ ${ }^{3}$ Department of Oral Anatomy, Dankook University College of Dentistry, Cheonan, Korea
}

\section{Research Article}

J Periodontal Implant Sci 2015;45:8-13

http://dx.doi.org/10.5051/jpis.2015.45.1.8

Purpose: The aim of this study was to evaluate the transfer of different occlusal forces in various skeletal malocclusions using finite element analysis (FEA).

Methods: Three representative human cone-beam computed tomography (CBCT) images of three skeletal malocclusions were obtained from the Department of Orthodontics, Yonsei University Dental Hospital, Seoul, South Korea. The CBCT scans were read into the visualization software after separating bones and muscles by uploading the CBCT images into Mimics (Materialise). Two separate three-dimensional (3D) files were exported to visualize the solid morphology of skeletal outlines without considering the inner structures. Individual dental impressions were taken and stone models were scanned with a 3D scanner. These images were integrated and occlusal motions were simulated. Displacement and Von Mises stress were measured at the nodes of the FEA models. The displacement and stress distribution were analyzed. FEA was performed to obtain the 3D deformation of the mandibles under loads of 100, 150, 200, and $225 \mathrm{~kg}$.

Results: The distortion in all three skeletal malocclusions was comparable. Greater forces resulted in observing more distortion in FEA.

Conclusions: Further studies are warranted to fully evaluate the impact of skeletal malocclusion on masticatory performance using information on muscle attachment and 3D temporomandibular joint movements.

Keywords: Computer simulation, Finite element analysis, Malocclusion.

\section{INTRODUCTION}

Occlusal force is the result of the combined action of the jaw elevator muscles modified by complex jaw biomechanics [1]. The investigation of occlusal force integrates several domains of expertise and can facilitate an improved understanding of the mechanics of mastication, facial morphology, periodontal status, and temporomandibular joint diseases. Especially during treatment planning for dental implants or during the maintenance phase for patients with periodontitis, evaluating occlusal force is a critical part of the clinical assessment [2-4]. Since loading is one of the factors that determine the outcome of dental implants and the maintenance of the periodontium, careful consideration of the biomechanics relating to loading is critical; however, few, in any, studies have investigated the biomechanics of mastication $[5,6]$.

In the field of orthodontics, it is important to evaluate the association between maloc-

This is an Open Access article distributed under the terms of the Creative Commons Attribution Non-Commercial License (http://creativecommons.org/licenses/by-nc/3.0/). 
clusions and skeletal disproportion. A number of studies have been performed to establish a clear classification scheme [7,8]. Anteroposterior disproportions have been categorized into class I (normal), class II (retrusion of the mandible), and class III (protrusion of the mandible). These disproportions can affect facial morphology, soft tissue outlines, and occlusal patterns. A significantly altered pattern of occlusal force can significantly lower patients' quality of life, especially that of periodontally compromised patients [9].

A number of scientific studies have attempted to measure occlusal force in order to investigate the relationship between occlusal force and facial morphology. In order to study the effect of skeletal disproportions on masticatory force, casts and articulators have been routinely utilized to simulate masticatory movements. However, this methodology leads to inaccuracies because it is difficult to properly measure the exact occlusal force transferred from the teeth to the jaws. Recently, finite element analysis (FEA) has been introduced and used in various situations to assess the transfer of occlusal force, including onto implant prostheses and edentulous areas. This approach avoids the inaccuracies of conventional methods [10-12].

In the present study, FEA models were constructed using conebeam computed tomography (CBCT) images and dental scan images from three subjects with different molar occlusion relationships. The aim of this study was to evaluate the transfer of different occlusal forces in the three-dimensional (3D) reconstructed images obtained from CBCT and scanned dental models.

\section{MATERIALS AND METHODS}

Three representative patients with classes I, II, and III malocclusions were selected from patients who visited the Department of Orthodontics at Yonsei University. This study received the approval from the
Institutional Review Board, Dental Hospital, Yonsei University (reference number: 13-0070). The patients had no restorations, prostheses, or facial deformities. The skulls were scanned using a clinical CBCT scanner (Rayscan Symphony, Ray Co., Hwaseong, Korea) in the transverse plane with both a slice thickness and a scan increment of $2 \mathrm{~mm}$, resulting in 20-slice images. The CBCT scans were read into the visualization software (Dassault Systems, Waltham, MA, USA) using a HP Z800 workstation (Hewlett-Packard Co., Palo Alto, CA, USA); CPU, W5580 (3.2 GHz, turbo speed: $3.5 \mathrm{GHz}$, number of cores: 4); RAM, 32 GB; HDD, SSD, 128 GB; VGA, Quadro FX4800, 1.5 GB. Bones and muscles were separated by uploading the CBCT images into Mimics (Materialise, Leuven, Belgium). Two separate 3D files were exported to visualize the solid morphology of skeletal outlines without considering inner structures. This was performed to prevent calculation errors during the integration with the 3D scanned images of teeth. As well, the apical half of teeth during intercuspation was removed since it was not clearly distinguishable in the CBCT images. These procedures have also been described in our previous study [13]. The files created by the Mimics software were transformed into the STEP file format using 3-Matic (Materialise) and finally analyzed with Solidworks (Dassault Systèmes, Velizy, France). The extracted models were manipulated as separate upper and lower models. The shapes of the teeth were fixed onto the lower model.

Dental impressions were taken and cast models were fabricated from the patients. The cast models were then scanned using a 3D optical laser scanner (Orapix KOD-500, Seoul, Korea), and imported into MeshLab (ISTI-CNR, Pisa, Italy). The imported teeth images were aligned based on the tooth shapes imported from Mimics. The files were uploaded into Blender 3D (Blender, Amsterdam, Netherlands). Details of the modeling procedure are illustrated in Fig. 1. Three composite skull models were used to represent craniofacial structures (Fig. 2).
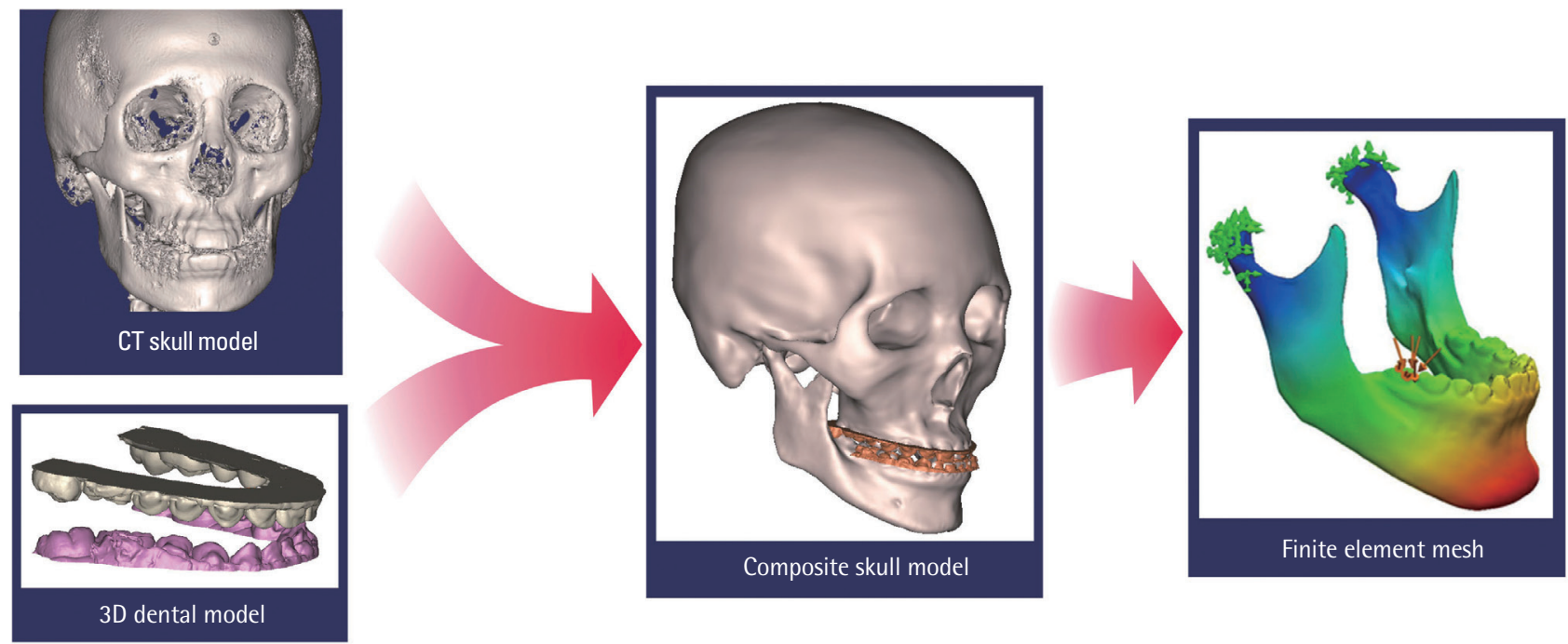

Figure 1. Dental modeling procedures used in this study. Cone-beam computed tomography (CT) images were obtained and integrated with three-dimensional (3D) information scanned from the dental model. 


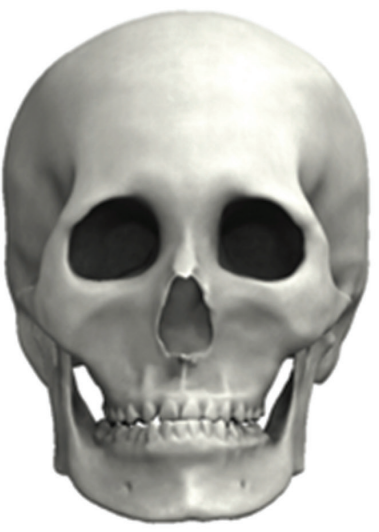

Class III

A

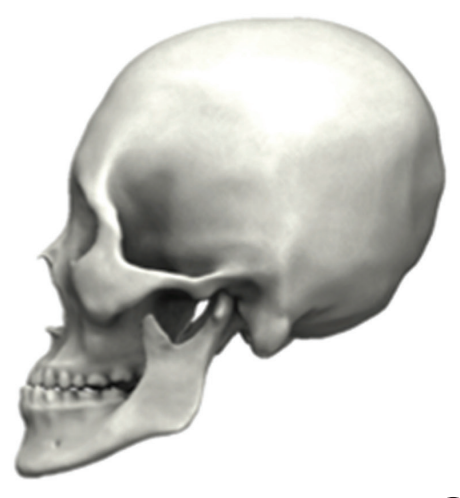

Class III
B

Figure 2. Three-dimensional reconstruction of human skull cone-beam computed tomography images from three representative individuals with skeletal malocclusions of classes I, II, and III. (A) Frontal views of three individuals. (B) Lateral views of three individuals with distinctive occlusal relationships.

To simulate motion, two separate models were employed in the initial joint position. The movement of the mouth was modeled based on results from previous studies [13]. The initial stop points of teeth were designated as initial pressure points and colored in order to be utilized in structural simulations. For the structural simulation, connected joints were selected and joints were designated in the lower model to simulate initial pressure points onto colored areas. In this study, it was difficult to clearly visualize the muscles and ligaments, so the endpoints were intentionally defined at places where teeth were occluded. Meshes were created with 677,852 total nodes and 474,152 total elements, each sized $1 \mathrm{~mm}$ with a tolerance of $0.05 \mathrm{~mm}$ (Fig. 3).

The following four weights were applied: $908 \mathrm{~N} ; 1,470 \mathrm{~N} ; 1,960 \mathrm{~N}$; and 2,205 N (100 kg, 150 kg, 200 kg, and $225 \mathrm{~kg}$, respectively). The application of loads was vertically aligned from top to bottom. Displacement and Von Mises stress were measured at the nodes. The displacement and stress distribution were analyzed using ANSYS ver. 11.0 (ANSYS Inc., Canonsburg, PA, USA) and processed on an HP xw6400 workstation (Hewlett-Packard Co.). The properties of the materials in the simulation were based on the properties of human bone determined when extracted teeth were physically fractured in a compression machine at 2,205 $\mathrm{N}$. The specifications of the ceramic bone were as follows: tensile strength of $1.7234 \times 10^{8} \mathrm{~N} / \mathrm{m}^{2}$, compressive strength of $5.5149 \times 10^{8} \mathrm{~N} / \mathrm{m}^{2}$, Young's modulus of $2.2059 \times 10^{11} \mathrm{~N} / \mathrm{m}^{2}$, Poisson's ratio of 0.22 , mass density of $2,300 \mathrm{~kg} /$ $\mathrm{m}^{3}$, and shear modulus of $9.0407 \times 10^{10} \mathrm{~N} / \mathrm{m}^{2}$.

\section{RESULTS}

The 3D reconstruction of human skulls showed distinctive differences among the types of skeletal relationships (Fig. 2). Images from skulls with a class I relationship showed ideal anterior-posterior intermaxillary positions while images from skulls belonging to classes II and III showed skeletal malocclusions. The skull with a class III malocclusion illustrated the typical long-faced subject.

FEA was performed using the data found in the analysis of static equilibrium. Each mandible was represented as an assemblage of subdivisions referred to as finite elements. The movement of the mandible was captured from the 3D scan. Complications presented by patients with each skeletal relationship were simulated. Following the confirmation of mandible movement and projection, the primary and total loading areas were visually illustrated using FEA. 

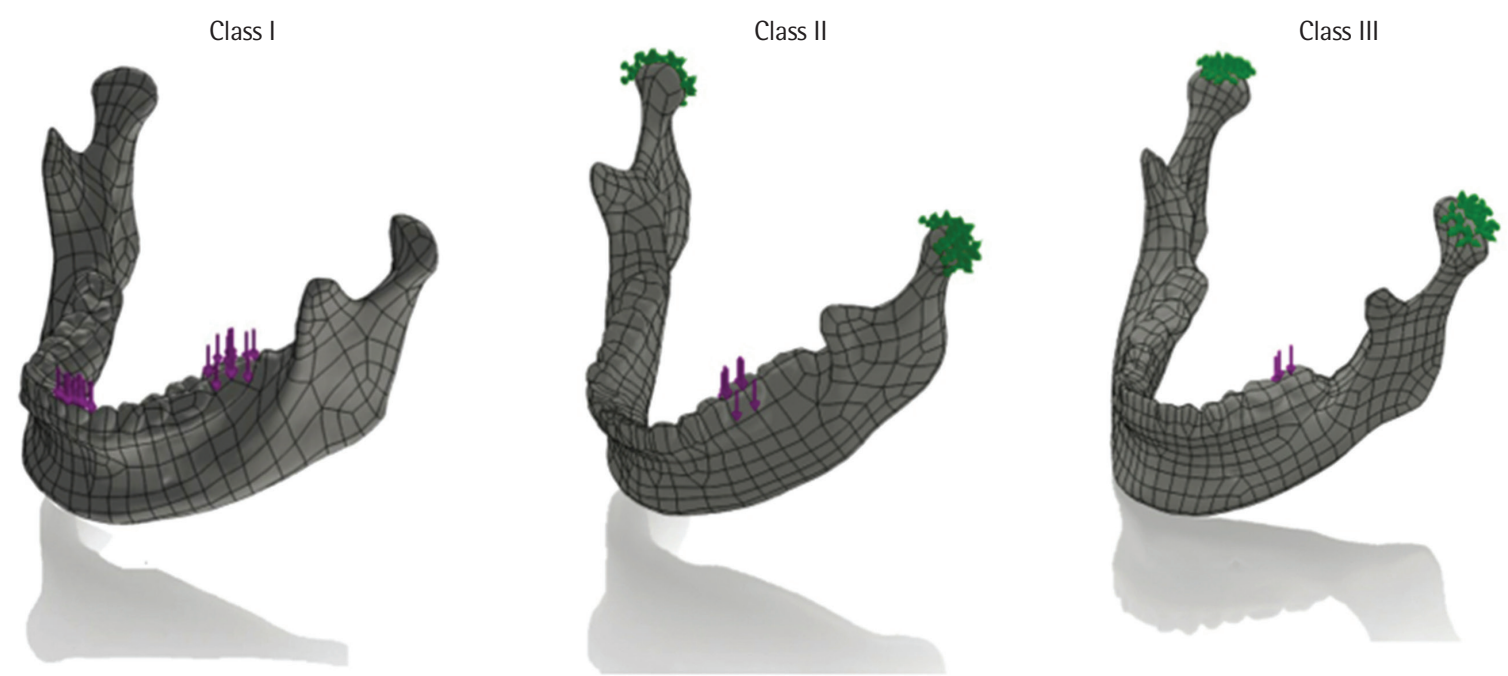

\begin{tabular}{|lcccc|}
\hline & Mass $(\mathrm{kg})$ & Volume $\left(\mathrm{m}^{3}\right)$ & Density $\left(\mathrm{kg} / \mathrm{m}^{3}\right)$ & Weight $(\mathrm{N})$ \\
\hline Class I & 0.178109 & $7.74389 \mathrm{e}-005$ & 2,300 & 1.74547 \\
Class II & 0.132445 & $5.75847 \mathrm{e}-005$ & 2,300 & 1.29796 \\
Class III & 0.150817 & $6.55726 \mathrm{e}-005$ & 2,300 & 1.47801 \\
\hline
\end{tabular}

Figure 3. Three-dimensional reconstructions of these images were produced with a surface triangularization technique. The mechanical properties assigned are shown in the figure.
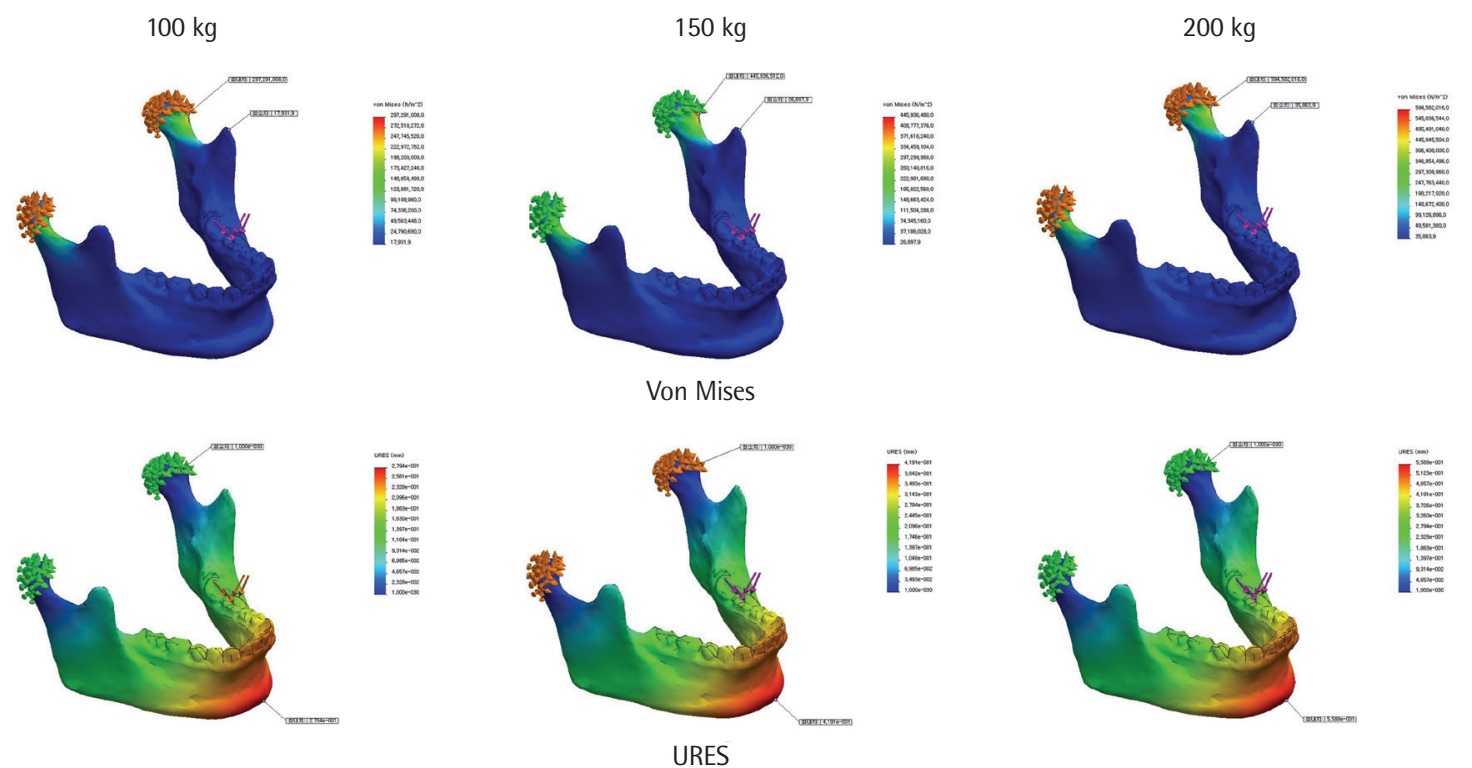

Figure 4. Pattern of Von Mises stress and maximum part deflection (URES; mm). Color-coded areas indicate the amount of distortion as shown in the inset index bar.

Distortion measurements led to the following results: in class I, a 0.54-mm distortion was observed after loading $100 \mathrm{~kg}$, a $0.80-\mathrm{mm}$ distortion was observed after loading $150 \mathrm{~kg}$, a $1.07-\mathrm{mm}$ distortion was observed after loading $200 \mathrm{~kg}$, and a 1.2-mm distortion was observed after loading $225 \mathrm{~kg}$.
In class II, a 0.26-mm distortion was observed after loading 100 $\mathrm{kg}$, a $0.38-\mathrm{mm}$ distortion was observed after loading $150 \mathrm{~kg}$, a 0.52 distortion was observed after loading $200 \mathrm{~kg}$, and a $0.58-\mathrm{mm}$ distortion was observed after loading $225 \mathrm{~kg}$.

In class III, a 0.54-mm distortion was observed after loading 100 
$\mathrm{kg}$, a $0.80-\mathrm{mm}$ distortion was observed after loading $150 \mathrm{~kg}$, a $1.07-\mathrm{mm}$ distortion was observed after loading $200 \mathrm{~kg}$, and a $1.2-$ $\mathrm{mm}$ distortion was observed after loading $225 \mathrm{~kg}$. These results are illustrated in Fig. 4. The magnitude of the distortions is color-coded.

\section{DISCUSSION}

The objective of this study was to evaluate the impact of different occlusal forces on the distortion of mandibles using FEA of CBCT images of the skeleton and 3D scanned dental images, which were later simulated by motion capture data. The FEA results showed a distinctive distortion pattern for each skeletal malocclusion.

Previous studies have shown that CBCT images are appropriate for generating $3 \mathrm{D}$ models of teeth $[14,15]$. However, the resolution is not always clear enough to distinguish all relevant details, although CBCT images are widely used in various dental fields. The visualizations of dental surfaces and occlusion are not ideal because CBCT images are subject to scattering from artifacts at the occlusal level $[16,17]$. In the present study, dental information was manually acquired from impression models of each patient which were later scanned by a 3D scanner. The integration of digital dental casts into CBCT scans has been attempted by various authors, and high-quality results have proven to be readily achievable $[18,19]$. The technique of this integration may be of clinical relevance because it may provide important information for planning dental treatment and investigating oral disease. In particular, joint movement was simulated in the present study to fully mimic the movement of the temporomandibular joint and occlusion patterns.

Mechanically, bite force is substantianlly affected by the geometry of the lever system of the mandible, including the orientation of the muscles [20]. Since mechanical factors such as the ratio of anterior/ posterior facial height, mandibular inclination, and the gonial angle are directly connected to the maximum bite force, more vertical and more acute gonial angles result in greater occlusal force $[21,22]$. A number of studies have measured occlusal forces using strain gauges or miniature bite forks [23-25]. However, these methods have certain limitations since they cause an open bite of at least $5 \mathrm{~mm}$. Moreover, these techniques cannot measure the bite force during maximum intercuspation. Therefore, indirect measurement methods have been introduced, involving the use sound transmission during mastication [26]. However, such methods can result in discrepancies due to measurement errors. Recently, improved measurement methods have been introduced, involving pressure sensitive sheets (Dental Prescale $50 \mathrm{H}$ type R, Fuji Film Co., Tokyo, Japan) and charge-coupled device cameras [27]. In the present study, the authors evaluated the distortion from various occlusal forces in three different skeletal malocclusions. Since we used skeletal and dental information from Korean patients, the results from this study can provide important information for further research.

Previous studies have shown that greater gonial angles provide an inferior level system for the elevator muscles and smaller perpendicular vectors to the occlusal table [28]. As well, patients with no abnormalities experience greater occlusal forces than patients with dolichofacial abnormalities, whereas patients with brachyfacial abnormalities have even greater bite forces [29]. This information is useful in the planning of implant treatment or rehabilitation after periodontal therapy [2,3]. CBCT images are routinely obtained before the implant treatment planning procedure. Dental impressions are also simultaneously taken prior to the procedure. Therefore, using such dental data, clinicians can predict the occlusal pattern, occlusal force, and the highly or minimally loaded areas using 3D simulation as proposed by the current authors in the present study. Such procedures may become an essential part of total treatment planning in the near future.

Despite its limitations, the current study shows that the simulation of CBCT images and dental scans can be successfully integrated and the occlusal forces can be clearly simulated in different skeletal malocclusions. Further studies are warranted to fully evaluate the impact of skeletal malocclusion on masticatory performance using information about muscle attachment and 3D temporomandibular joint movement.

\section{CONFLICT OF INTEREST}

No potential conflict of interest relevant to this article was reported.

\section{ACKNOWLEDGEMENTS}

This study was supported by a grant (HI11C1643) of the Korea Health Technology R\&D Project, Ministry for Health, Welfare \& Family Affairs, Republic of Korea, and a grant of the Basic Science Research Program through the National Research Foundation of Korea (NRF) funded by the Ministry of Education (No. 20110010739).

\section{ORCID}

Jung-Chul Park http://orcid.org/0000-0002-2041-8047

Hyun-Seung Shin http://orcid.org/0000-0002-1410-9731

Jung-Yul Cha http://orcid.org/0000-0001-8761-3819

Jong-Tae Park http://orcid.org/0000-0002-3295-6512

\section{REFERENCES}

1. Sonnesen L, Bakke M. Molar bite force in relation to occlusion, craniofacial dimensions, and head posture in pre-orthodontic children. Eur J Orthod 2005;27:58-63.

2. Takeuchi N, Ekuni D, Yamamoto T, Morita M. Relationship between the prognosis of periodontitis and occlusal force during the maintenance phase: a cohort study. J Periodontal Res 2010;45:612-7.

3. Takeuchi N, Yamamoto T. Correlation between periodontal status and biting force in patients with chronic periodontitis during the maintenance phase of therapy. J Clin Periodontol 2008;35:215-20. 
4. Misch CE. The effect of bruxism on treatment planning for dental implants. Dent Today 2002;21:76-81.

5. Duyck J, Van Oosterwyck H, Vander Sloten J, De Cooman M, Puers $R$, Naert I. Magnitude and distribution of occlusal forces on oral implants supporting fixed prostheses: an in vivo study. Clin Oral Implants Res 2000;11:465-75.

6. Davies SJ, Gray RJ, Linden GJ, James JA. Occlusal considerations in periodontics. Br Dent J 2001;191:597-604.

7. Sassouni V. A classification of skeletal facial types. Am J Orthod 1969;55:109-23.

8. Arnett GW, Bergman RT. Facial keys to orthodontic diagnosis and treatment planning--Part II. Am J Orthod Dentofacial Orthop 1993; 103:395-411.

9. English JD, Buschang PH, Throckmorton GS. Does malocclusion affect masticatory performance? Angle Orthod 2002;72:21-7.

10. Choi DS, Cha BK, Jang I, Kang KH, Kim SC. Three-dimensional finite element analysis of occlusal stress distribution in the human skull with premolar extraction. Angle Orthod 2013;83:204-11.

11. Geng JP, Tan KB, Liu GR. Application of finite element analysis in implant dentistry: a review of the literature. J Prosthet Dent 2001; 85:585-98.

12. Eskitascioglu G, Usumez A, Sevimay M, Soykan E, Unsal E. The influence of occlusal loading location on stresses transferred to implant-supported prostheses and supporting bone: a three-dimensional finite element study. J Prosthet Dent 2004;91:144-50.

13. Park JT, Lee JG, Won SY, Lee SH, Cha JY, Kim HJ. Realization of masticatory movement by 3-dimensional simulation of the temporomandibular joint and the masticatory muscles. J Craniofac Surg 2013;24:e347-51.

14. Gateno J, Xia J, Teichgraeber JF, Rosen A. A new technique for the creation of a computerized composite skull model. J Oral Maxillofac Surg 2003;61:222-7.

15. Santler G, Karcher H, Gaggl A, Kern R. Stereolithography versus milled three-dimensional models: comparison of production method, indication, and accuracy. Comput Aided Surg 1998;3: 248-56.

16. Gateno J, Xia JJ, Teichgraeber JF, Christensen AM, Lemoine JJ, Liebschner MA, et al. Clinical feasibility of computer-aided surgical simulation (CASS) in the treatment of complex cranio-maxillofacial deformities. J Oral Maxillofac Surg 2007;65:728-34.

17. Noh $\mathrm{H}, \mathrm{Nabha} W, \mathrm{Cho} J \mathrm{H}, \mathrm{Hwang} \mathrm{HS}$. Registration accuracy in the integration of laser-scanned dental images into maxillofacial cone-beam computed tomography images. Am J Orthod Dentofacial Orthop 2011;140:585-91.

18. Rangel FA, Maal TJ, Berge SJ, Kuijpers-Jagtman AM. Integration of digital dental casts in cone-beam computed tomography scans. ISRN Dent 2012;2012:949086.

19. Swennen GR, Mollemans W, De Clercq C, Abeloos J, Lamoral P, Lippens $F$, et al. A cone-beam computed tomography triple scan procedure to obtain a three-dimensional augmented virtual skull model appropriate for orthognathic surgery planning. J Craniofac Surg 2009;20:297-307.

20. Koc $D$, Dogan $A$, Bek B. Bite force and influential factors on bite force measurements: a literature review. Eur J Dent 2010;4:223-32.

21. Braun $S$, Bantleon HP, Hnat WP, Freudenthaler JW, Marcotte MR, Johnson BE. A study of bite force, part 2: relationship to various cephalometric measurements. Angle Orthod 1995;65:373-7.

22. Braun S, Bantleon HP, Hnat WP, Freudenthaler JW, Marcotte MR, Johnson BE. A study of bite force, part 1: relationship to various physical characteristics. Angle Orthod 1995;65:367-72.

23. Brudevold F. A basic study of the chewing forces of a denture wearer. J Am Dent Assoc 1951;43:45-51.

24. Anderson DJ. Measurement of stress in mastication. II. J Dent Res 1956;35:671-3.

25. Floystrand F, Kleven E, Oilo G. A novel miniature bite force recorder and its clinical application. Acta Odontol Scand 1982;40: 209-14.

26. Gibbs $\mathrm{CH}$, Mahan $\mathrm{PE}$, Lundeen $\mathrm{HC}$, Brehnan $\mathrm{K}$, Walsh EK, Holbrook WB. Occlusal forces during chewing and swallowing as measured by sound transmission. J Prosthet Dent 1981;46:443-9.

27. Harada $K$, Watanabe M, Ohkura K, Enomoto S. Measure of bite force and occlusal contact area before and after bilateral sagittal split ramus osteotomy of the mandible using a new pressure-sensitive device: a preliminary report. J Oral Maxillofac Surg 2000;58: 370-3.

28. Throckmorton GS, Finn RA, Bell WH. Biomechanics of differences in lower facial height. Am J Orthod 1980;77:410-20.

29. Furtado GC, Furtado $A$, Abu El Haje O, Butignon LE, Pesqueira AA, Paranhos LR. Relationship between the morphology of the maxillary central incisor and horizontal and vertical measurements of the face. Indian J Dent Res 2014;25:178-83. 